\title{
Morbidades gestacionais e seus impactos para a vida da mulher
}

\author{
Management morbidity and its impacts for women's life \\ Morbías gestacionales y sus impactos para la vida de la mujer
}

Recebido: 19/12/2021 | Revisado: 27/12/2021 | Aceito: 03/01/2022 | Publicado: 04/01/2022

Jéssica Pessoa Neves Cadengue

ORCID: https://orcid.org/0000-0003-3087-9928

Universidade Federal de Alagoas, Brasil

E-mail: jessypessoa2018@gmail.com

Amuzza Aylla Pereira dos Santos

ORCID: https://orcid.org/0000-0001-6299-7190

Universidade Federal de Alagoas, Brasil

E-mail: amuzza.pereira@eenf.ufal.br

Isabel Comassetto

ORCID: https://orcid.org/0000-0002-2389-9384

Universidade Federal de Alagoas, Brasil E-mail: isabelcomassetto@gmail.com

Maria Elisângela Torres de Lima Sanches

ORCID: https://orcid.org/0000-0001-8987-3825 Universidade Federal de Alagoas, Brasil E-mail: eli.sanches23@gmail.com.

Karlayne Reynaux Vieira de Oliveira

ORCID: https://orcid.org/0000-0002-8920-5154 Universidade Federal de Alagoas, Brasil E-mail: karlayne2006@gmail.com

Thayná Mayara Resende de Gusmão ORCID: https://orcid.org/0000-0003-4164-3320 Universidade Federal de Alagoas, Brasil E-mail: thaynamrg@gmail.com Isabela Soares Gomes Alves

ORCID: https://orcid.org/0000-0002-2388-9928 Universidade Federal de Alagoas, Brasil E-mail: isabelasoaresg@hotmail.com

Nathalia Lima da Silva

ORCID: https://orcid.org/0000-0002-5163-7103 Universidade Federal de Alagoas, Brasil E-mail: nathalialimaa17.nl@gmail.com

\begin{abstract}
Resumo
Objetivo: Descrever os impactos causados pelas morbidades gestacionais para a mulher em todo o seu contexto de vida. Método: Estudo exploratório, com abordagem qualitativa, realizado com 20 mulheres internadas na maternidade pública, no período de setembro a outubro de 2018, através de uma entrevista guiada por roteiro semiestruturado. Os dados foram analisados seguindo a técnica de análise de conteúdo de Bardin, a discussão teve como referencial metodológico a Teoria da consecução do papel maternal. A pesquisa foi encaminhada ao Comitê de Ética em Pesquisa da Universidade Federal de Alagoas, através da Plataforma Brasil para apreciação, obtendo-se a sua aprovação através do $\mathrm{n}^{\circ}$ 87702318.8.0000.5013. Resultados: Após a análise das informações obtidas, foi realizado a caracterização das participantes em dados sociodemográficos e gineco-obstétricos, e selecionada a unidade temática: Impactos da descoberta da morbidade frente ao processo gestacional e as suas subcategorias: impacto físico, financeiro, familiar, sexual e psicológico. Conclusão: Verificou-se que existem uma série de impactos físicos, financeiros, familiares, sexuais e psicológicos que passam a fazer parte da vida das mulheres após a descoberta da morbidade gestacional, e que para supri-los, faz-se necessário dar voz a estas mulheres, uma vez que isto irá permitir apreender e compreender, a partir de suas experiências peculiares, a vivência de eventos médicos e não médicos aos quais encontram-se expostas e que podem gerar vulnerabilidades as quais devem ser consideradas.
\end{abstract}

Palavras-chave: Gestantes; Saúde da mulher; Enfermagem; Morbidade; Impactos na saúde.

\begin{abstract}
Objective: To describe the impacts caused by gestational morbidities for women in their entire life context. Method: Exploratory study with a qualitative approach, carried out with 20 women hospitalized in the public maternity hospital, from September to October 2018, through an interview guided by a semi-structured script. The data were analyzed following Bardin's content analysis technique, the discussion had the Theory of the achievement of the maternal role as a methodological framework. The research was sent to the Research Ethics Committee of the Federal University of
\end{abstract}


Alagoas, through Plataforma Brasil, for consideration, and approval was obtained under $\mathrm{N}^{\mathrm{o}}$. 87702318.8.0000.5013. Results: After analyzing the information obtained, the participants were characterized in sociodemographic and gynecological-obstetric data, and the thematic unit was selected: Impacts of the discovery of morbidity in the face of the gestational process and its subcategories: physical, financial, family impact, sexual and psychological. Conclusion: It was found that there are a series of physical, financial, family, sexual and psychological impacts that become part of women's lives after the discovery of gestational morbidity, and that to overcome them, it is necessary to give voice to these women, since this will allow them to apprehend and understand, from their peculiar experiences, the experience of medical and non-medical events to which they are exposed and which can generate vulnerabilities which must be considered.

Keywords: Pregnant woman; Women's health; Nursing; Morbidity; Impacts on health.

\section{Resumen}

Objetivo: Describir los impactos que provocan las morbilidades gestacionales en las mujeres en todo su contexto vital. Metodología: Estudio exploratorio con abordaje cualitativo, realizado con 20 mujeres hospitalizadas en la maternidad pública, de septiembre a octubre de 2018, a través de una entrevista guiada por un guión semiestructurado. Los datos fueron analizados siguiendo la técnica de análisis de contenido de Bardin, la discusión se basó en la Teoría del logro del rol materno. La investigación fue enviada al Comité de Ética en Investigación de la Universidad Federal de Alagoas, a través de Plataforma Brasil, para su consideración y se obtuvo la aprobación con el número 87702318.8.0000.5013. Resultados: Luego de analizar la información obtenida, las participantes fueron caracterizadas en datos sociodemográficos y ginecológico-obstétricos, y se seleccionó la unidad temática: Impactos del descubrimiento de la morbilidad ante el proceso gestacional y sus subcategorías: físico, económico, impacto familiar, sexual y psicológica. Conclusión: Se encontró que existen una serie de impactos físicos, económicos, familiares, sexuales y psicológicos que pasan a formar parte de la vida de las mujeres luego del descubrimiento de la morbilidad gestacional, y que para superarlos es necesario dar voz a estas mujeres, ya que esto les permitirá aprehender y comprender, a partir de sus vivencias peculiares, la vivencia de eventos médicos y no médicos a los que están expuestos y que pueden generar vulnerabilidades que deben ser consideradas.

Palabras- clave: Mujeres embarazadas; Salud de la mujer; Enfermería; Morbilidad; Impactos en la salud.

\section{Introdução}

Em um contexto de debates sobre direitos sexuais e reprodutivos da mulher, observou-se acentuada importância e gravidade da ocorrência do agravo durante seu ciclo gravídico-puerperal, o qual possa comprometer tanto sua gestação quanto seu feto. Dentre os fatores de risco gestacional, podemos citar os agravos obstétricos diretos, exemplificados como a hipertensão arterial, hemorragia, infecção puerperal e aborto (Brasil, 2012).

Independentemente da forma como se iniciou a gestação, a mulher grávida passa a experimentar uma série de expectativas e anseios, frutos das alterações fisiológicas mediadas por condições físicas ou hormonais, a nível corporal e de ordem psíquica, da expectativa de futuro sobre o concepto e até mesmo o medo do parto, principalmente nas primíparas. Deste modo, a gravidez é vista pelas mulheres como um momento de transição extremamente significativo, que exige adaptações diversas (Cabral et al., 2018)

A descoberta da morbidade torna-se um momento crítico não só para os pais, mas também, para toda a equipe de enfermagem, já que são eles que passam a maior parte do tempo com a gestante, e a chegada desse novo cenário demandará conhecimento técnico-científico e humanização para que haja o devido acolhimento e um cuidado eficaz para com essa gestante e sua família (Oliveira \& Mandú, 2015).

Frente as necessidades de cuidados que devem ser adotadas durante a gestação de alto risco, pode-se perceber que não é uma adaptação fácil. Exige mudanças na alimentação, no repouso, nas atividades cotidianas e diárias e, até mesmo, nas relações interpessoais, que demandam esforço e atenção das gestantes. Desta forma, observa-se a necessidade do profissional enfermeiro, estar atento a realidade e necessidade de cada mulher (Wilhelm et al., 2021).

De todo modo, é sabido que a realização do pré-natal, é a principal maneira de prevenção de agravos relacionados à saúde do binômio mãe-bebê pois contribui para redução de mortalidade materna e fetal por causas evitáveis ou revertidas com a implementação de mudanças e bom acompanhamento profissional durante o período gravídico (Santos, Almeida, Oliveira \& Campos, 2021). 
Diante do exposto, surgiu o seguinte questionamento: Quais os impactos na saúde das mulheres após a descoberta da morbidade gestacional? Para responder ao questionamento acima foi elaborado o seguinte objetivo: descrever os impactos causados pelas morbidades gestacionais na vida da mulher.

\section{Método}

Trata-se de um estudo qualitativo de caráter exploratório. O local escolhido para a realização da pesquisa foi a maternidade do Hospital Universitário Prof. Alberto Antunes (HUPAA), localizado na cidade de Maceió, Alagoas. A escolha dessa unidade se deu, pois, a mesma faz parte do Hospital escola vinculado à Universidade Federal de Alagoas, onde são realizados atendimentos de alto risco.

Foram selecionadas como participantes do estudo 20 mulheres, dentre elas gestantes e puérperas, que haviam descoberto alguma morbidade em sua gestação e que estavam recebendo assistência na maternidade do HUPAA.

Foram incluídas na pesquisa mulheres acima de 12 anos de idade, na companhia de seu responsável legal, e que tiveram complicações gestacionais que poderiam ser tanto relacionadas à mãe quanto ao bebê e excluídas as gestantes com problemas psicológicos que impossibilite a realização da entrevista e que apresentem óbito fetal intrauterino por causa da morbidade fetal.

Após aprovação do comitê de ética, CAAE n 87702318.8 .0000 .5013 , para que se iniciasse a pesquisa foi solicitado a autorização na direção do referido Hospital onde a pesquisa foi realizada. A partir disto foi realizado um estudo piloto com três mulheres com o objetivo de identificar a assertividade do instrumento de coleta de forma que o mesmo contemplasse o objetivo da pesquisa.

A primeira fase realizou-se a partir da consulta aos prontuários das mulheres internadas na maternidade do HUPAA, onde foi verificado os possíveis diagnósticos das morbidades relacionados ao binômio. Porém, nem sempre foi possível realizar um contato prévio para o esclarecimento do objetivo da pesquisa, o que teve que ocorrer no mesmo momento em que o formulário seria aplicado, após autorização da participante.

A coleta de dados foi realizada no período de setembro a outubro de 2018. Na segunda fase houve a interação com as mulheres e em ocasião, com os seus respectivos responsáveis, onde houve apresentação da intenção da pesquisa e leitura do Termo de Consentimento Livre e Esclarecido (TCLE) e Termo de Assentimento Informado Livre e Esclarecido (TALE).

Após aceitarem participar da pesquisa, os devidos documentos foram assinados e deu-se início a entrevista a qual foi guiada por um roteiro semiestruturado, que continha os dados de identificação sócio demográfica (nome, cor, idade, escolaridade, ocupação, religião), dados gineco-obstétricos, dados sobre a gestação atual e hábitos de vida. Neste momento também, se procedeu o registro de informações relevantes e escuta qualificada relacionados ao objeto da pesquisa. Para que os dados fossem colhidos na íntegra, de forma a não perder nenhuma expressão apresentada pela voluntária, a entrevista foi gravada com um gravador de áudio do celular, e posteriormente transcrita. As entrevistas foram realizadas na enfermaria onde elas estavam acomodadas, tanto da maternidade quanto do Alojamento Conjunto (ALCON). Buscou-se a todo momento priorizar o conforto e a privacidade delas.

A análise dos dados foi fundamentada na técnica de Análise de Conteúdo, modalidade temática, descrita por Bardin como um conjunto de técnicas de análise das comunicações, que utiliza procedimentos sistemáticos e objetivos de descrição do conteúdo das mensagens, através de três passos: 1- A pré-análise; 2- A exploração do material; e 3- O tratamento dos resultados, a inferência e a interpretação (Bardin, 2009).

A pré- análise é a fase de organização e sistematização das ideias iniciais, de modo que as conduza a um esquema de desenvolvimento das operações sucessivas. É seguida pela escolha desses documentos, que estarão estritamente ligados ao objetivo a que se propõe; pela formulação das hipóteses, dos índices e indicadores; e finalizada com a preparação do material (Bardin, 2009). 
A exploração do material é uma fase longa que consiste em operações de codificação (transformação dos dados brutos e sua agregação em unidades), decomposição ou enumeração de regras previamente formuladas; ou seja, é a aplicação das decisões tomadas na fase anterior (Bardin, 2009).

Por último, os resultados brutos são tratados de maneira a serem significativos e válidos. A partir de então o analista pode propor inferências (tirar por conclusão; indução; deduzir pelo raciocínio) e adiantar interpretações a propósito dos objetivos previstos - ou que digam respeito a outras descobertas inesperadas (Bardin, 2009).

Após a análise dos dados sob esta ótica, a discussão teve como referencial metodológico a Teoria da consecução do papel maternal. Os conceitos desta Teoria estão centralizados no vínculo entre o binômio mãe-filho, promoção da competência, confiança e alegria no papel da maternidade. A teorista, Mercer, relata que o processo de se tornar mãe acontece ao longo da vida da mulher e visa o desenvolvimento da sua identidade materna (Mercer \& Walker, 2006).

\section{Resultados}

Participaram da pesquisa 20 mulheres dentre elas, 12 gestantes e oito puérperas, sendo sua faixa etária variando entre 16 e 43 anos de idade. Relacionado ao nível de escolaridade, seis delas haviam concluído o ensino médio, cinco não o havia completado, quatro referiram o nível fundamental completo, três o ensino fundamental incompleto, apenas uma com ensino superior incompleto e uma era analfabeta.

Com relação ao estado civil, oito das entrevistadas afirmaram ter união estável, sete afirmaram ser casadas e cinco afirmaram ser solteiras. No que diz respeito à fonte de renda, a maioria delas 14 afirmou ser dona de casa, e moravam com seu companheiro ou com seus familiares; quatro possuíam trabalho remunerado no mercado formal, na função de promotora de vendas, uma, uma merendeira, uma atendente e duas afirmaram ser estudantes.

Identificou-se também que 12 dessas gestações não foi planejada, e apenas oito delas afirmaram que não desejaram a gravidez atual. O número de consultas de pré-natal também foi questionado: seis das entrevistadas realizou menos de seis consultas de pré-natal, sete delas foi a seis consultas e sete a mais de seis consultas de pré-natal. No que se refere aos antecedentes obstétricos, observou-se que oito das entrevistadas eram primigestas, seis delas eram secundigestas e cinco, multigestas. Vale ressaltar que dentre estas multigestas, uma estava na sua $11^{\mathrm{a}}$ gestação.

Das morbidades mais prevalentes relacionadas a mulher, 14 foram diagnosticadas com Síndromes Hipertensivas registradas no prontuário, dentre elas sete com Pré-Eclâmpsia e sete com Doença Hipertensiva Específica Gestacional (DHEG), e apenas um caso de Diabetes Gestacional. Já os diagnósticos relacionados ao bebê, identificou-se dois RNs com cardiopatia congênita, também dois casos de malformação fetal, e um de anencefalia. Levando em consideração as características do grupo estudado, realizou-se a análise temática dos depoimentos das participantes, o que possibilitou a categorização de suas vivências a partir do diagnóstico da morbidade gestacional. Dessa forma com a análise e tratamento dos dados coletados, emergiu-se uma unidade temática, a saber: Impactos da descoberta da morbidade frente ao processo gestacional e suas subcategorias: impacto físico, financeiro, familiar, sexual e psicológico.

\section{Impactos da descoberta da morbidade frente ao processo gestacional \\ Impacto físico}

A participantes relataram a sua adaptação e da sua família ao novo cotidiano exigido a partir de suas limitações físicas. Percebe-se que elas passaram por limitações as quais exigiram repouso e as impossibilitaram de realizar suas atividades diárias, no entanto, tiveram apoio dos seus familiares para suprir tais demandas.

- Comecei a inchar logo cedo, aí esse negócio de casa, eu arrumava e meu marido mantinha... os pratos ele lavava (Lírio) 
- Eu parei de fazer as coisas em casa por que eu tava me cansando muito, muito mesmo. Eu começava a varrer a casa e na metade eu parava por não conseguia (Lisianto)

- Tudo que eu conseguia fazer só era cuidar do almoço, lavava roupa a pulso, com as pernas inchada doendo... pronto, mas nada eu fazia (Lavanda)

\section{Impacto financeiro}

Esta categoria retrata as dificuldades enfrentadas por elas para receberem acompanhamento pré-natal de alto risco, além do desafio de ter que se ausentar de seu trabalho, e, portanto, da sobrecarga financeira sofrida por elas e sua família. Ao serem questionadas sobre a fase que estavam vivendo e os impactos financeiros, relataram:

- Eu gastei muito por que eu vinha pra aqui em carro pago, lá a prefeitura não libera o carro pra trazer para as consultas. Aí eu tive ajuda do meu tio, do meu irmão que mandava dinheiro pra mim, pra eu pagar as passagens, as irmãs da igreja arrecadaram dinheiro pra mim, por que senão eu não tinha condições de vir fazer o pré-natal aqui (Girassol)

- [...] Eu tive que me afastar do trabalho, saí muito antes de ter, por que meus pés incharam muito [...] aí assim, tudo isso é uma mudança né, porque eu trabalhando, já ajudava mais em casa aí depois que eu deixei de trabalhar ficou tudo pra o meu esposo, aí as coisas ficaram mais difíceis (Margarida)

\section{Impacto familiar}

Quando questionadas sobre o apoio de seus familiares, a maioria afirmou ter o recebido, sobretudo do companheiro e da mãe, algumas até referiram, com bastante entusiasmo, ter passado a receber mais atenção após as complicações na gravidez. Relataram ainda que eles ajudavam nas atividades domésticas, cuidando de seus filhos, na sua alimentação, financeiramente e principalmente, dando o apoio moral e psicológico. Apenas uma delas relatou, com bastante pesar, que não recebeu ajuda de nenhum familiar.

- Depois desse presente (bebê), melhorou muito. Tô recebendo muito mais atenção. O povo fica bajulando, né(risos), depois da doença (Rosa)

- Minha relação com meu esposo ficou mais forte ainda, a gente ficou mais unido, um com o outro (Margarida)

- Não, sozinha mesmo. Só eu e Deus [...] A gente fica abalada né, meio triste, por que não tem apoio da família pra ajudar. Minha mãe nem chega na minha casa pra perguntar: e aí, como tais? Vai ter esse menino quando? Ai a pessoa fica triste, né (Jade).

\section{Impacto sexual}

Identificou-se ainda que ao ser constatado o alto risco gestacional, surgiu o receio de prejudicar o bebê e até medo de abortar, devido à prática da atividade sexual, resultando na diminuição da sua frequência ou suspensão por completo. Quando questionadas se receberam orientações sobre esse assunto durante o pré-natal, a maioria relatou ter sido orientada de que não havia riscos, mas que mesmo assim não haviam superado seus receios. Outras, a depender da gravidade do seu caso, receberam orientações sobre a abstenção da atividade sexual e as respeitaram fielmente.

- Desde que eu fiquei grávida, com dois meses, eu nem podia mais ter relação, por que ficava sangrando quando eu 
tinha relação, aí a médica proibiu até agora. Ele entendeu, por que ele sabia que eu não podia (Rosa)

- [...] Eu ficava com medo de sangrar ou começar a doer. A gente sempre tinha relação 3, 4 vezes por semana, aí diminui pra 1, 2, com bem cuidado, sempre ele entendendo, sem pressão com isso (Lírio)

- Ele quer ter relação, mas eu não quero não, só quando meu filho nascer. Dizem que não prejudica, mas prejudica sim. A médica disse que era bom ter relação 3 vezes na semana, mas eu não faço nenhuma vez por semana (Lavanda)

\section{Impacto psicológico}

Esta categoria retrata os impactos durante o processo de internamento, e o que esse confinamento representa para elas; e também no momento da descoberta do agravo. Observou-se que o período de internamento é um pontente extressor para a maioria. Foram identificados sentimentos de ansiedade para a saúde e bem-estar do feto, dificuldade para gerir o confinamento no hospital, e sensação de estar "prisioneiro", assim como de vulnerabilidade e solidão por estarem longe de casa e de seus filhos. No entanto, algumas demonstraram mais confiança, aceitação e entendimento de que o processo de internamento era necessário e benéfico.

- Passou 3 dias que eu me interno, pronto, meu psicológico não é mais o mesmo. Parece que tá tudo trancado lá dentro, eu só penso em chorar [...] vem filho lá fora, meu filho tá sem ir pra escola... (Rosa)

- Ficar internada também mexe com a gente ne [...] parece que um dia que a pessoa passa internada, é uma semana. É o tempo todo ali só deitada, tomando medicamento e levando furada... aí é complicado, né (Margarida)

- Eu não vou dizer que não quero ir pra casa, mas não quero ir com eles sem saúde ou até sem eles, ne... Agora eu tô conseguindo aceitar mais (Lírio)

Ainda nessa perspectiva de questionamentos a respeito das influências psicológicas sofridas em todo esse processo, as falas obtidas de uma entrevistada demonstraram um cenário diferenciado ou pode-se dizer, mais preocupante do que os demais. Quando questionada (Rosa) a respeito das repercussões psicológicas de sua gravidez, a mesma fez relatos importantes, os quais incluem a tentativa de suicídio e pensamentos que colocam em risco a integridade física do seu bebê.

- Passei por uma fase muito ruim na minha vida que eu cheguei a me jogar em uma moto. Tem vez que eu tô aqui com ele, aí fico aqui pensando... eu fico com medo dos meus pensamentos (Rosa)

- Aí eu com ele aqui, imaginando coisas terríveis, eu tenho medo dos meus pensamentos (Rosa)

- Tem vez que aquelas psicólogas vêm que eu fico na expectativa, esperando elas virem, já pra conversar. Eu disse a elas que eu nunca desejei tanto que elas viessem (Rosa)

Também se identificou repercussões psicológicas ocorridas com a descoberta da morbidade. Verificou-se a repetição dos sentimentos de medo, temiam tanto pela sua morte quanto pela perda do bebê; sentimento de tristeza e episódios de choro compulsivo também foram bastante mencionados.

- A minha gravidez todinha foi eu com medo de perder meu filho, eu morria de medo (Jasmim)

- Ao descobrir a complicação eu só chorava, fiquei muito aperreada (Rosa)

- Assim que eu descobri que tava grávida foi aquela alegria, aquela felicidade, por que era uma coisa que a gente 
queria muito [...] foi um presente, ne, uma alegria. Aí depois quando a médica botou na parte da cabeça (aparelho USG), aí já foi aquela tristeza por cima (Margarida)

\section{Discussão}

A gestação de alto risco, em muitos casos provoca alterações multidimensionais na mãe e também em todas as pessoas que a acompanham. Tal evento implica no surgimento de diversos sentimentos para a gestante, tais como: solidão devido ao isolamento, inatividade forçada, consumação do parto, medo da morte ou das possíveis sequelas em decorrência da prematuridade e culpabilidade por não ser capaz de ter uma gravidez normal (Rezende, 2014).

É sabido que a família se constitui como o principal suporte de auxílio durante o período gestacional. No entanto, nem todas desfrutaram desse envolvimento familiar durante a gestação. Houveram relatos de sensação de abandono por parte de alguns familiares como o seu companheiro e sua mãe. Tal situação é apontada pelo Ministério da Saúde como um fator de risco enquadrado nas características individuais e condições sociodemográficas desfavoráveis (Brasil, 2012).

O processo de tornar-se mãe pode gerar um conflito pelo fato de requerer o sacrifício de uma imagem até então construída de si, a qual levou uma vida inteira para ser construída (Mercer \& Walker, 2006). Nessa perspectiva, as entrevistadas passaram por essa desconstrução fisiológica e psicológica de sua imagem acrescentando-se a isso, o atenuante de suas morbidades.

Por isso a necessidade da assistência dos profissionais de saúde e principalmente, dos enfermeiros à essa população. Pois, são estes que passam a maior parte do tempo junto às mães, e com isso, assumem especial relevância no apoio e orientação tanto à mulher quanto ao restante da família, devendo considerar cada mulher única e como o seu centro de interesse.

Destacando assim, a importância da realização do pré-natal e o acompanhamento da equipe de enfermagem, visando diminuir os eventos estressores, realizado através de atividades de educação em saúde, com foco na prevenção de agravos devido a morbidade que acomete a mulher, promovendo confiança, autonomia e acompanhamento constante (Silva et al., 2021).

Analisando o impacto financeiro, observou-se que se faz necessário olhar essas questões pelo ângulo das vulnerabilidades, e superar o seletivo raciocínio de risco, quer dizer, identificar os aspectos e as condições que podem comprometer a saúde das mulheres e, ainda, reconhecer a relação que há entre eles, e que estes fatores tanto afetam a sua saúde física e emocional, quanto limitam as suas possibilidades de tomada de decisão e de autocuidado (Oliveira \& Mandú, 2015).

As novas demandas de cuidado ampliam os gastos, e elas nem sempre dispõem de recursos financeiros para supri-los. Em uma pesquisa realizada por Alves et al. (2021) aponta sobre a questão da situação financeira fragilizada da maioria das mulheres com alguma situação de risco relacionada à saúde. É muito importante que mulheres nessas condições recebam assistência humanizada e integral. Pois, situações com as citadas no texto, além de indicarem vulnerabilidade social, também afetam as condições psicológicas e físicas, ocasionando dessa forma, maiores riscos à saúde do binômio (Oliveira \& Mandú, 2015).

O processo de transição para a maternidade é rico em oportunidades de intervenções para a enfermagem. É pertinente ressaltar a fundamental importância de tais intervenções para que essa transição ocorra de forma saudável e que tenha êxito. O apoio social tem sido descrito na literatura como um dos principais mediadores entre a vivência de uma situação de crise e a adaptação efetiva da família; como foi possível observar a partir dos relatos obtidos no 'Impacto familiar' (Oliveira \& Mandú, 2015).

Os resultados do estudo de Oliveira et al. (2013) corroboram com esta informação, pois constata que o grupo de apoio aos pais proporciona o melhor enfrentamento, colaborando para a redução do estresse e isolamento social envolvido nesse processo, já que os pais passam a lidar melhor com a situação. 
Tornou-se possível identificar claramente a influência dos círculos concêntricos referidos na Teoria da Consecução do Papel Materno. Observa-se que as respostas confirmam a importância do microssistema no contexto familiar, o qual é o ambiente mais próximo e, portanto, imediato no processo de tornar-se mãe. Os achados nos relatos comprovam essa perspectiva, uma vez que a presença dos familiares, e sobretudo do companheiro, ao oferecer apoio seja de ordem emocional, psicológica, financeira, ou na realização das tarefas domésticas, foi primordial para elas, visto que as mesmas se encontravam em uma situação vulnerável de sua vida (Oliveira et al., 2013)

No âmbito da sexualidade nesse contexto, Prado, Lima e Lima (2013) afirmam que para as mulheres de maneira geral, o afeto, o carinho e o respeito mútuo são aspectos que influenciam a atividade sexual do casal. Quando estes fatores se fazem presentes, têm-se o aumento do desejo sexual, no qual a mulher está pronta e aberta para as experiências que a gestação proporciona. Já Vieira et al. (2016) afirmam que a satisfação do exercício sexual durante a gestação está diretamente ligada com medos e receios. Pois determinadas dúvidas, crenças ou mitos interferem na prática da sexualidade.

Sabe-se que há várias décadas as políticas de saúde no Brasil, com relação a mulher estavam atreladas unicamente às ações de atendimento a gestação e parto, ou seja, restrita ao processo reprodutivo. Baseavam-se no aspecto biológico e no papel social de mãe, e apesar de estarmos no século XXI, ainda convivemos com essa realidade. Faz-se necessário desmistificar tabus e preconceitos principalmente os que estão enraizados pela nossa cultura no que diz respeito à gravidez de alto risco.

Em complementação ao que foi anteriormente falado, observa-se nos discursos que há uma grande frequência de abstenções, que na maioria das vezes são radicais e desnecessárias. Também foi identificado a necessidade de acesso dessas mulheres a informações mais detalhadas sobre a própria saúde e a de seu filho durante o pré-natal e também na atenção especializada. Pois em muitos contextos, por falta de informação, a mulher vive uma condição de insegurança e medo que afeta diretamente no seu relacionamento conjugal, podendo trazer sérias consequências.

A gravidez por si só compreende um período de maior tensão e ansiedade, especialmente em mulheres que a vivenciam pela primeira vez. Sabe-se que face a um diagnóstico de gravidez de risco a mulher vive essas emoções negativas de forma mais intensa, especialmente em situações que requerem internamento. Com base nisto, o estudo realizado por Lobão (2017) afirma que associado ao internamento e ao tratamento, acentua-se o medo, a ansiedade e o estresse. Nas situações de repouso no leito, as mulheres vivenciam a perda da autonomia, a separação com a sua rede de suporte, a troca de papéis no seio familiar, a impotência e a perda de privacidade.

Pensando nesse aspecto, a Rede Cegonha instituiu no Artigo $1^{\circ}$ da Portaria n ${ }^{\circ} 1020$ de 29 de maio de 2013:

Diretrizes para a organização da Atenção à Saúde na Gestação de Alto Risco e define os critérios para a implantação e habilitação dos serviços de referência à Atenção à Saúde na Gestação de Alto Risco, incluída a Casa de Gestante, Bebê e Puérpera (CGBP).

Trata-se de uma residência provisória de apoio às gestantes, puérperas e recém-nascidos em situação de risco que demandam assistência diária em serviço de saúde de alta complexidade, mas que não exigem vigilância constante em ambiente hospitalar. Também em casos de puérperas com bebê internado na Unidade de Terapia Intensiva Neonatal que necessitam de informação e orientações relacionadas aos cuidados especiais com seu bebê (Brasil, 2013). Por isso, configura-se uma oportunidade para o binômio passar por esse período necessário de assistência hospitalar, só que não neste ambiente que é hostil para a maioria. Ainda sobre o Impacto psicológico, foi observado a partir dos relatos de uma participante, sintomas sugestivos de depressão; segundo a Organização Mundial de Saúde (Brasil, 2013) a depressão é a principal causa de problemas de saúde e incapacidade em todo o mundo. É um importante fator de risco para o suicídio e é considerado um transtorno mental comum.

Para os autores do Maternal Adjustment and Maternal Attitudes (MAMA), os valores obtidos na versão ante-natal do questionário permitem a previsão do ajustamento materno no pós-parto, uma vez que ao ser observado que as gestantes que 
forneceram respostas menos positivas nas subescalas relativas à relação conjugal e às atitudes com a gravidez e o bebê, apresentaram valores mais elevados de sintomatologia depressiva após o parto (Figueiredo, Mendonça, Sousa, 2004).

O estudo feito por Martinez et al. (2016) reafirma que durante o pós-parto, a condição psiquiátrica mais comum é a depressão, e que apesar de uma proporção significativa das mães, enquanto usuárias da atenção primária de saúde (APS), apresentarem alto risco para tal, ainda sim os transtornos depressivos geralmente não são detectados ou tratados, apesar da disponibilidade de tratamentos eficazes. Como foi observado nas falas da participante, os pensamentos negativos, que perecem assustadores para ela, motivaram a procura de ajuda profissional. De acordo com a OMS (2017), os programas de saúde reprodutiva devem reconhecer a importância dos problemas de saúde mental nas mulheres que desejam engravidar até as puérperas, e incorporar esta dimensão na prestação de cuidados.

Segundo Guerra et al. (2014) existem algumas intervenções que podem promover a saúde mental da mulher com ganhos significativos, sendo eles: identificação precoce dos fatores de risco, preparação para o desempenho do papel, identificação da rede de suporte social, incentivo ao envolvimento do pai na vigilância da gravidez e nos cuidados à criança, realização de cursos para preparação em grupo do papel de pai e realização de visitas domiciliares no puerpério.

$\mathrm{Na}$ abordagem relacionada ao impacto decorrente da descoberta da morbidade, Ferreira, Elias, Corrêa (2018) afirma que o descompasso entre as expectativas e as realidades da maternidade pode ser vivido como uma crise pessoal. A perda das características do filho e da gestação desejada e anteriormente idealizada pelos desejos e sonhos da mãe, causa uma lesão no ego destas. O idealizado pelos sonhos se desconstrói dando lugar a uma nova realidade na qual deve ser respeitada e compreendida nos seus limites, permitindo um novo lugar com a construção de novas expectativas.

O estudo MAMA atestou que na subescala 'atitudes para com a gravidez e o bebê, a qual avalia as reações, atitudes e preocupações da mulher frente à gravidez e o filho, o questionamento relacionado com o estado de saúde do bebê apresentou os piores resultados médios, o que demonstra a elevada preocupação e ansiedade da grávida com o estado de saúde e normalidade do filho (Figueiredo et al., 2004).

Com base nos estágios da aquisição do papel materno, a gestante pode sofrer frustações no estágio de antecipação. Isto pode ocorrer devido à quebra das expectativas a respeito do bebê e da gestação após a descoberta da morbidade, causando assim um grande abalo psicológico, como foi observado. Este fato também pode ser influenciado pela má assistência fornecida pelos profissionais que a acompanham, sobretudo, dos enfermeiros, pois, segundo Mercer, estes são os profissionais mais habilitados para lidar com a mulher durante a gravidez, parto e puerpério.

Como já mencionado anteriormente, Ramona Mercer com sua Teoria propõe a necessidade de os profissionais de enfermagem levem em consideração o ambiente familiar, a escola, o trabalho, a igreja e outras entidades da comunidade como elementos importantes na adoção desse papel. O qual é entendido como um processo interativo e evolutivo que ocorre durante certo período de tempo, no qual a mãe encontra-se numa transformação dinâmica e uma evolução da pessoa-mulher em que implicará na conquista do papel materno.

Por isso, torna-se essencial o diálogo entre os profissionais e a gestante, pois feito isso, haverá o incentivo da autonomia destas mulheres para que expressem seus pensamentos, necessidades e dúvidas. Implementar o diálogo durante a assistência não é algo simples, depende de modificações na rotina do serviço e na atitude dos profissionais, onde estes, por vezes, impregnados pela assistência curativista e biomédica acabam ignorando que envolta da doença existe um paciente repleto de sentimentos e expectativas.

\section{Conclusão}

$\mathrm{O}$ estudo permitiu identificar os impactos relatados pelas mulheres que vivenciaram a descoberta de morbidades gestacionais, tais como: Síndromes Hipertensivas, Diabetes gestacional, cardiopatia congênita e mal formações fetais. Os 
impactos causados a partir desse momento vão desde limitações nos seus afazeres domésticos até a depressão; sendo categorizados nas seguintes subcategorias: Impacto físico, financeiro, familiar, sexual e psicológico.

A família e a rede social mostraram-se um importante suporte para o enfrentamento de todos os impactos vivenciados por essas mulheres. É bem verdade que, quando um problema vivenciado por um indivíduo é partilhado com os membros da família, torna-se mais fácil administrá-lo e solucioná-lo.

Neste contexto é importante que nas dificuldades e necessidades da mulher que enfrenta uma gestação de risco, esta receba o apoio de sua família. Percebeu-se no presente estudo que a família se mostrou envolvida e focada na participação do cuidado às gestantes na grande maioria dos casos.

Dar voz às mulheres que vivenciam uma gestação de maior risco permite apreender e compreender, a partir de suas experiências peculiares, a vivência de eventos médicos e não médicos aos quais se encontram expostas e, que podem gerar vulnerabilidades as quais devem ser consideradas. No relato de suas vivências gestacionais, as mulheres expressaram vários aspectos pessoais, intersubjetivos, familiares, institucionais e sociais entrelaçados. Por esses motivos, o cuidado durante o acompanhamento da gestante deve abarcar essas questões que são tão peculiares a cada mulher e seu desfecho gestacional.

No mais, deixamos como sugestão de realização de outros estudos afim de conhecer a realidade de cada local e das mulheres com morbidades no contexto da gestação.

\section{Referências}

Alves, T. O. et al. (2021). Gestação de alto risco: epidemiologia e cuidados, uma revisão da literatura. Brazilian Journal of Health Review. https://doi.org/10.34119/bjhrv4n4-040

Bardin, L. (2009). Análise de conteúdo. (70a ed.).

Brasil. Ministério da Saúde. (2012) Secretaria de Atenção à Saúde. Departamento de Ações Programáticas Estratégicas. Gestação de alto risco: manual técnico. Brasília.

Brasil, Ministério da Saúde. Portaria n ${ }^{\circ} 1020$ de 29 de maio de 2013. Institui os princípios e diretrizes para a organização da Atenção à saúde na gestação de alto risco e define os critérios para a implantação e habilitação da Casa de Gestante, Bebê e Puérpera (CGBP). Em conformidade com a Rede Cegonha, na forma de anexos 10 e 11 do anexo II desta Portaria e do anexo LXII DA Portaria de Consolidação n ${ }^{\circ} 6$.

Cabral, S. A. A. O, Alencar, M. C. B, Carmo, L. A, Barbosa, S. E. S, Barros, A. C. C. V, \& Barros, J. K. N. (2018). Receios na Gestação de Alto Risco: Uma Análise da Percepção das Gestantes no Pré-Natal. Rev. Mult Psic https://doi.org/10.14295/idonline.v12i40.1051

Ferreira, R. M., Elias, F. J. M, \& Corrêa, A. A. M. (2018). Das representações mentais na gestação as frustrações pós parto: um campo para a psicanálise. Rev Saúde e Meio Ambiente.

Figueiredo, B., Mendonça, M., \& Sousa R. (2004). Versão portuguesa do Maternal Adjustment and Maternal Attitudes (MAMA). Psicologia, saúde \& doenças http://www.scielo.mec.pt/pdf/psd/v5n1/v5n1a03.pdf

Guerra, M., Braga, M., Quelhas, I., \& Silva, R. (2014). Promoção da saúde mental na gravidez e no pós-parto. Revista Portuguesa de Enfermagem de Saúde Mental http://www.scielo.mec.pt/pdf/rpesm/nspe1/nspe1a19.pdf

Lobão, F. M. (2017). A esperança numa gravidez com complicações [dissertação] Porto: Escola superior de enfermagem do Porto https://comum.rcaap.pt/bitstream/10400.26/18942/1/Relat\%C3\%B3rio\%20Est\%C3\%A1gio_\%20Francisca\%20Lob\%C3\%A3o.pdf

Martinez, P., Vöhringer, P. A, \& Rojas, G. (2016). Barriers to access to treatment for mothers with postpartum depression in primary health care centers: a predictive model. Rev. Latino-Am. Enfermagem. http://dx.doi.org/10.1590/1518-8345.0982.2675

Mercer, R. T. \&\& Walker, L. O. (2006). A Review of Nursing Interventions to Foster Becoming a Mother. Journal of Obst Ginec e Neo Nursing https://doi.org/10.1111/j.1552-6909.2006.00080.x

Oliveira, D. C, \& Mandú E. N. T. (2015). Mulheres com gravidez de maior risco: vivências e percepções de necessidades e cuidado. Escola Anna Nery. https://www.scielo.br/j/ean/a/Zmx4qBMrpVCywS6kMWY7bFw/?format=pdf\&lang=pt

Oliveira, K., Veronez, M., Higarashi, I. H., \& Corrêa, D. A. M. (2013). Vivências de familiares no processo de nascimento e internação de seus filhos em UTI neonatal. Esc Anna Nery http://www.redalyc.org/articulo.oa?id=127728366007.

Organização Mundial de Saúde. Com depressão no topo da lista de causas de problemas de saúde, OMS lança a campanha "Vamos conversar". 2017. https://nacoesunidas.org/depressao-e-tema-de-campanha-da-oms-para-dia-mundial-da-saude-de-2017/

Prado, D. S., Lima, R. V., \& Lima, L. M. M. R. (2013) Impacto da gestação na função sexual feminina. Rev.Bras. de Ginec. $e$ Obst http://www.scielo.br/pdf/rbgo/v35n5/03 
Research, Society and Development, v. 11, n. 1, e15611124944, 2022

(CC BY 4.0) | ISSN 2525-3409 | DOI: http://dx.doi.org/10.33448/rsd-v11i1.24944

Santos, M. das D. dos, Almeida, D. R. de, Oliveira, M. L. de, \& Campos, S. M. S. de. (2021). Perfil das gestantes com Síndrome Hipertensiva Específica da Gestação atendidas nas Unidades Básicas de Saúde na Cidade de Cáceres-Mato Grosso, Brasil. Research, Society and Development, 10(12), e192101220230. https://doi.org/10.33448/rsd-v10i12.20230

Silva, M. P. B et al. (2021). O pré-natal e a assistência de enfermagem à gestante de alto risco. Research, Society and Development, 10(9). 10.33448/rsdv10i9.17173.

Vieira, T. G., Santos, M. L. L., Nóbrega, M. M., \& Medeiros, H. R. L. (2016). Percepção de gestantes acerca da sexualidade e o papel do enfermeiro como educador na atenção primaria à saúde. Rev. Temas em Saúde http://temasemsaude.com/wp-content/uploads/2016/08/16215.pdf

Wilhelm, L. A., Prates, L. A., Alves, C. N., Scarton, J.., \& Cremonese, L. (2021). Motivações para realizar práticas de cuidado na gestação de alto risco. Research, Society and Development, 10(1), e17710111527. https://doi.org/10.33448/rsd-v10i1.11527 